\title{
Western Faculty Profile: Dr. Irena Creed
}

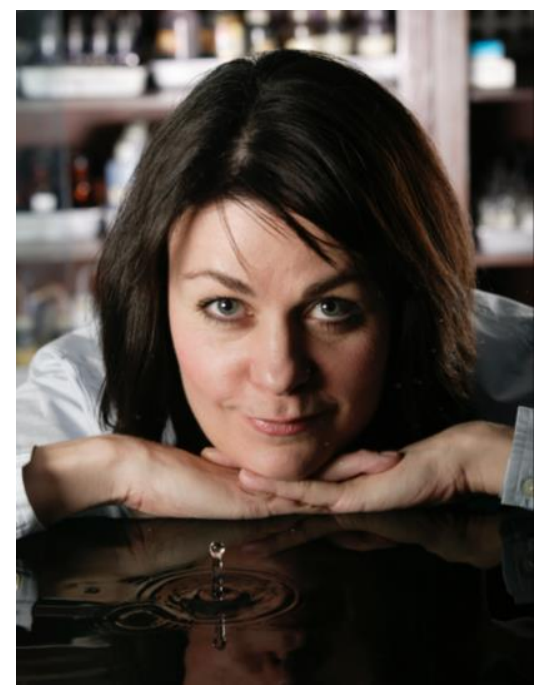

\section{Background}

Dr. Irena Creed is a Professor of Biology, Geography, and Earth Sciences at Western University. She is a Tier II Canada Research Chair in Watershed Sciences, as well as the founder of the Watershed Research Facility - an advanced environmental monitoring, analytical, and modelling facility at Western. With a focus on developing a predictive understanding of watershed systems, Dr. Creed conducts research at sites around the world. WURJHNS First Year Representative Janis Chang had the opportunity to interview Dr. Creed and learn more about her research and her career.

Decked out as she was in pink cashmere and dainty footwear, Dr. Irena Creed's first foray into fieldwork did not seem like an ideal start. However, thanks to excellent undergraduate professors, Dr. Creed ended up "falling into" environmental science nonetheless. Her career now takes her from the classroom to study environmental problems throughout North America, Europe, Asia and Africa.

Dr. Creed emphasizes the importance of integrated systems. With watershed systems as her entry point, she follows the path water takes from rain to surface water flowing through the landscape. Her work is often closely tied with real life technological applications and environmental policy. For example, she is currently working as part of a trans-border research university network on the Great Lakes Futures Project, which focuses on Canadian and American water stewardship of the Great Lakes. With the environmental stress caused by factors from pollution to invasive species, scientists predict that a "dire future" lies ahead for the Great Lakes if government policies are not changed to reflect the most pressing ecological concerns. Another project Dr. Creed is working on is studying domesticated landscapes and the impact of human development on fragile ecosystems. To that end, she is currently working with the government of Alberta to develop a wetland policy that uses advanced technology, such as satellite remote sensing and geographic information systems, to conduct environmental triage-deciding which critical wetlands must be saved to preserve the balance of natural water pathways.

Dr. Creed also believes in the concept of "scientific tithing," which suggests that researchers should dedicate ten percent of their time toward solving societal problems. She has integrated this principle into her career; for the past seven years, she has contributed her research energy on the ground in developing countries. Notably, she has conducted significant fieldwork in Kenya at Lake Naivasha, part of a chain of freshwater shallow lakes and a Ramsar wetland of international ecological significance. Through a partnership with Kenyan universities, Western students have volunteered their time in Kenya, and Kenyan students have come to Western to learn about cutting-edge technologies. This work is making a difference. When Dr. Creed first began this study, Lake Naivasha was in danger of "dying," suffering from what Dr. Creed labels "sick ecosystem syndrome." The 
Western-based team of faculty and students discovered that chemicals used to grow flowers were making their way through the community and that improper usage was polluting the lake water. Now that a problem has been identified, steps can be taken to draft policies and to work with locals to improve the health of the ecosystem.

Dr. Creed's research affects not only environmental health, but also human health. Many health concerns stem from the importance of water as a fundamental aspect of life. She studies climate change and atmospheric pollution, which are fundamentally changing the way watersheds function. Atmospheric pollution can convert into potent greenhouse gases or results in changes in the microbial community composition of surface water. This might trigger increased levels of organisms such cyanobacteria, which produce liver- and brain-affecting toxins that are thought to play a role in diseases such as Alzheimer's and amyotrophic lateral sclerosis.

For Dr. Creed, research diversity is exciting, and she divides her research work into three components: field work, laboratory work, and computer work. By splitting her time and energy between these three aspects, Dr. Creed is able to think about the big picture and not lose focus on any one component. She encourages her students and any aspiring young researchers to strive for diversity by covering at least two out of the three parts of her research model.

Outside of her work, one of the things Dr. Creed is most passionate about is her family. With two daughters, it is not surprising that one of her current pursuits is a Female Guest Professorship in Sweden. She is a mentor and promotes attracting and retaining more women in science. According to Dr. Creed: "You can be a mother, doctor, scientist - all of those things." Considering her extensive fieldwork and varied research projects, one of the most remarkable things about Dr. Creed is how she balances her time. Dr. Creed is adept at creating a work-life balance in other ways too. In her free time, she has taken to running. Her goal is to work up to running a full marathon, "hopefully in some exotic locale." According to Dr. Creed, the demands of her job necessitate movement, and she advises that "a healthy body makes for a clear mind."

Dr. Creed loves her work, and she is always seeking out creative new opportunities - to the point where she now juggles a large diversity of projects. Perhaps even more than research, however, Dr. Creed loves her teaching job. "It's a privilege to teach," she says, and she is always energized by young people and their passion. Dr. Creed's own passion follows her to the classroom as well. She taught an ecosystem science course for many years, for which she made up for the lack of opportunities to take students into the field (the course was offered in winter!) by bringing the experts directly to the class. Her dedication extended outside of the classroom - inviting these experts from around the world to her house for what she terms "showdown dinners," Dr. Creed gives students the chance to connect directly with experts in their fields of interest. With the diverse personalities and approaches represented at these dinners, Dr. Creed would be the first to admit that it can get a little crazy. But she also hastens to add: "Sometimes, when you're really passionate, insanity's just a part of it!"

Finally, when asked to give advice to students and aspiring researchers, Dr. Creed says: "Be engaged in the world. Be aware of what is going on around you - locally, nationally and internationally." She seeks students who strive to develop a "big picture" understanding, who look for connections everywhere. In her opinion, good scientists must be aware of their world around them and be good listeners: "They must be curious, read, read everything, and use their imagination." To Dr. Creed, having the right attitude is more critical than having specific skill sets. She tells students to have a strong work ethic, to be kind, to be respectful, and to be team players. The students who have excelled have had "a fire in their belly," a drive to succeed. The last thing Dr. Creed said was this: "You must have a strong spirit that can overcome the challenges I guarantee will come. True failure is when you stop trying. Don't ever stop trying."

To read more on Dr. Creed's lab and research, please visit her website at: http://www.uwo.ca/biology/faculty/creed/ 